\title{
WAMIS Database: Enhancing Sustainable Usage and Effective Management of Water Points
}

\author{
Ally S. Nyamawe \\ College of Informatics and Virtual Education \\ The University of Dodoma
}

\begin{abstract}
Effective management and sustainable usage of water points is vital for reliable supply of safe water to a public. Poor management of water points is named to be a contributor to the non-functioning of water points. Misallocation of efforts due to poor decision making such as concentrating water points in one village and leave demanding village unsaved is also a challenge. Despite of the devoted efforts that Tanzania has made to ensure sustainable and sufficient water availability, still the situation calls for more improved interventions. In this paper, WAMIS (Water-points Management Information System) is developed with a pivotal role to computerize water points' information handling and support precise decision making for effective water points management and sustainable usage.
\end{abstract}

\section{General Terms}

ICT for Development

\section{Keywords}

Water points, WAMIS, DWE, WDLC, SDLC.

\section{INTRODUCTION}

Water is the essential resource that cut across all aspects of human life. In different sectors including; industrial, agriculture, environmental conservation, mining and domestic, water is a compulsory requirement. There have been joint efforts all over the global to ensure sustainable and sufficient availability of water and in good quality. Tanzania has no exceptions on this. Tanzania has been striving to establish numerous strategies and programs in the effort to improve water and sanitation services for better human survival and development. It is estimated that around $80 \%$ of the population in Tanzania are living in rural areas where there is limited accesses to clean water for domestic use and economic activities. To protect human life, constant tracking of water quality supplied to public is inevitable. Clean, safe, and adequate freshwater is vital to the survival of all living organisms and the smooth functioning of ecosystems, communities, and economies [1].Contaminated water may accelerate to the prevalent of water-washed, water-borne and water-related diseases. Safe water sources, basic sanitation, and improved hygiene practices can prevent water related diseases, other illness and death [2].

Sustaining the existing water supply points in Tanzania rural areas is still an enduring challenge. There is no reliable means of tracking the operation of water points and hence on time information availability such as water demand, amount of water produced and water quality is still questionable. Lack of these information, results to misallocation of efforts in institutionalizing water points in villages. The water point mapping data showed as much as fifty percent $(50 \%)$ of all water points in the 10 districts were not functioning, and there was a high inequality in the location/concentration of water points [3]. There have been a lot of efforts to ensure water points functionality such as; public awareness, registration of Community Owned Water Supply Organization (COWSO) and full utilization of local leaders. Despite of all these efforts, still the situation calls for more improved interventions. One major reason for the declining access to clean and safe water in rural areas in Tanzania is the sustainability challenges facing Rural Water Supply. The major reasons for nonfunctionality of many water points are not technical problems but poor management of water sources caused by accountability issues among actors in the water sector [3].

Information and Communication Technology (ICT) has the potential to help improve rural water supplies and address the systemic problems faced by the sector; but until now this potential has remained largely untapped in many developing countries [4]. To contribute to the sector, WAMIS (Waterpoints Management Information System) is developed. WAMIS is already operational in four selected districts (Kondoa, Bahi, Chamwino and Kiteto) in Tanzania central zone. The pivotal role of WAMIS is to computerize water points' information handling and support precise decision making for effective water points management.

\section{RELATED WORKS}

The water sector is among the huge areas in which the implementation of ICT solutions would provide noticeable improvements [5].

Rweyemamu F. [6] contends that, Tanzania in collaboration with developing partners joined their efforts to design a management, planning and monitoring tool so called Water Point Mapping System (WPMS). The system is more useful in showing the distribution of water points; functional and nonfunctional water points, and water points that need repair in each locality. WPMS allows for collection and establishment of baseline information for locating all water points which are existing and form a basis of improved service delivered. WPMS facilitates monitoring of distribution, status of water points and gives planners ability to improve water supply coverage. Water points are geo located using Global Positioning System. WPMS tracks data on functionality, management, technical specifications, quality and quantity of the water produced at each of the water points. However, updating of WPMS is named to be a hindering challenge for improved of efficiency, effectiveness and reliability. Moreover, [6] calls for more improved technology to facilitate real time updating and up-scaling WPMS to incorporate water quality issues. Additionally, the Tanzania's Ministry of Water managed to establish a number of ICT solutions for improving water sector, such as HYDATA, Water Quality Database and MaJIS. ICT is an effective tool in tracking status of services delivery to the public and ultimately supports equity distribution of water services [7].

Fantozzi M. et al. [8] contend that, improving water resources management is increasingly becoming a critical issue due to 
the increase of population and ageing of infrastructures. In understanding that, ICT solutions for Efficient Water Resources Management (ICeWater) was developed with the goal to increase the stability of freshwater supply to urban areas. ICeWater uses wireless sensor networks in monitoring water flow and provide a decision support system for the water utilities so that supply and demand patterns can be matched in real time. Additionally, through statistical methods water leakage can be predicted and therefore water network damages can be fixed even before they occur.

Emmanouilidis C. et al [9] developed ICT solution for monitoring water distribution network comprising of pipes for delivering water to consumers. Data from the meter and external the meter are collected and analyzed using statistical techniques to identify water network events such as leakage, quantity and quality of water flowing through the pipes.

\section{WAMIS}

In this section, WAMIS general overview is discussed. How it was conceptually designed and organized and its mode of operation is also presented.

\subsection{WAMIS General Overview}

The crucial role of WAMIS is to ensure the sustainable usage and effective management of water points. The available water points (Drilled, Constructed and Natural) are recorded and their quantity and quality parameters are constantly tracked. In addition to that, the population of people and livestock as the major users of domestic water is also recorded to allow for determining of present and future water demands. WAMIS gives a quick understanding of the status and trends of water availability (in terms of quality and quantity) and therefore appropriate intervention can be executed. Previous water points records (such as Depth and Water strikes), for drilled sources in particular; can be used as a benchmark for future drilling projects. Information to which parts of the village require more attention such as adding newly water points is also available at fingertip.

\subsection{WAMIS Development Life Cycle (WDLC)}

As the user requirements were not explicitly clear, ambiguous and conflicting, the throw away prototyping model was adopted. The Software Development Life Cycle (SDLC) as a general framework was used to guide the entire WDLC. SDLC provide a framework to create, plan and control any information system to be developed [10]. WDLC was made to have four key iterative phases of development (Requirements Elicitation and Analysis, System Design, Implementation and Testing).

\subsubsection{Requirements Elicitation and Analysis}

Several interviews with the District Water Engineers (DWEs) and Drilling Project Consultant to elicit WAMIS user's requirements were conducted. Key objectives of WAMIS were also explicitly defined to understand the expectations of the users. The elicited requirements were analyzed to remove ambiguities, conflicts and check for omissions. Systems Requirements Specification (SRS) document were obtained as an output of this phase and input for the subsequent phase (System Design). Use Cases Diagrams was used to analyze requirements and gave better understanding on what was going to be produced.

\subsubsection{System Design}

From the refined requirements, system was designed to produce architectural diagrams. WAMIS was designed on paper to produce several blue prints to help developers during implementation and show users how the system will look like. Among other diagrams drawn include, Entity Relationship Diagram (ERD) and Data Flow Diagrams (DFDs).

\subsubsection{Implementation}

During this phase, prototypes were developed and delivered to users for use. Users were given time to work with the prototypes and give their opinions on what needed to be improved, omitted or added. As the user continued to use the delivered prototypes the requirements were continually refined until when the user found that the objectives were fulfilled. It is in this phase, front end (Graphical User Interfaces) and back end (underlying database) were developed to form a prototype and later a complete system (WAMIS).

\subsubsection{Testing}

Different levels of testing were adopted, Unit testing, Integration testing, System testing and Acceptance testing. To ensure that WAMIS delivers user's expectations, black box testing was performed to check the completeness of system's functionalities and correctness of the outputs. Furthermore, white box testing was adopted to uncover errors from within the codes such as logical and typographical errors.

\subsection{WAMIS Conceptual Design}

In this section, only selected diagrams (Data Flow Diagram, Use Cases and Entity Relationship Diagram) are presented.

\subsubsection{Data Flow Diagram (DFD)}

DFD was used to model system functions and shows how data flows in and out of the system. From this modeling, the system's boundaries were put clear and business processes were also defined. In this part only context diagram is presented. As depicted in Figure 1, WAMIS context diagram is composed of three entities, District Water Engineer (DWE), Administrator and Decision Maker. DWE is responsible to fetch and collect data of water points (including quantity and quality parameters) available in the district, as well as people and livestock population. These data will then be inputted into WAMIS by DWE for storage and computation. Administrator is responsible to manage databases as WAMIS support multiple databases. In addition to that, Administrator manages system users and performs appropriate system setups, for example setting of water consumption in $\mathrm{m}^{3} /$ Day for both people and livestock unit. On the other hand, Decision Maker accesses WAMIS for report retrieval for the purpose of decision making. 


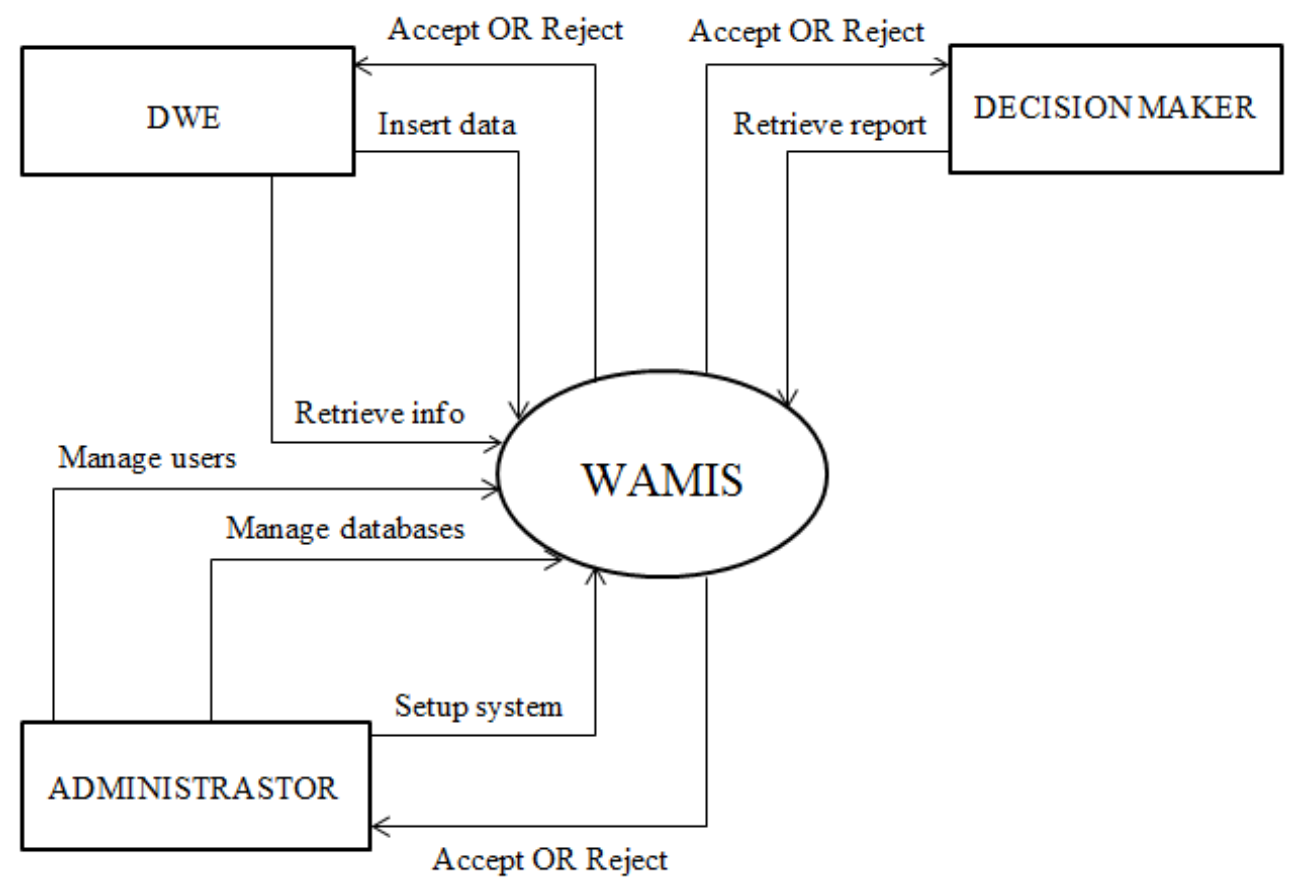

Figure 1: WAMIS Context Diagram

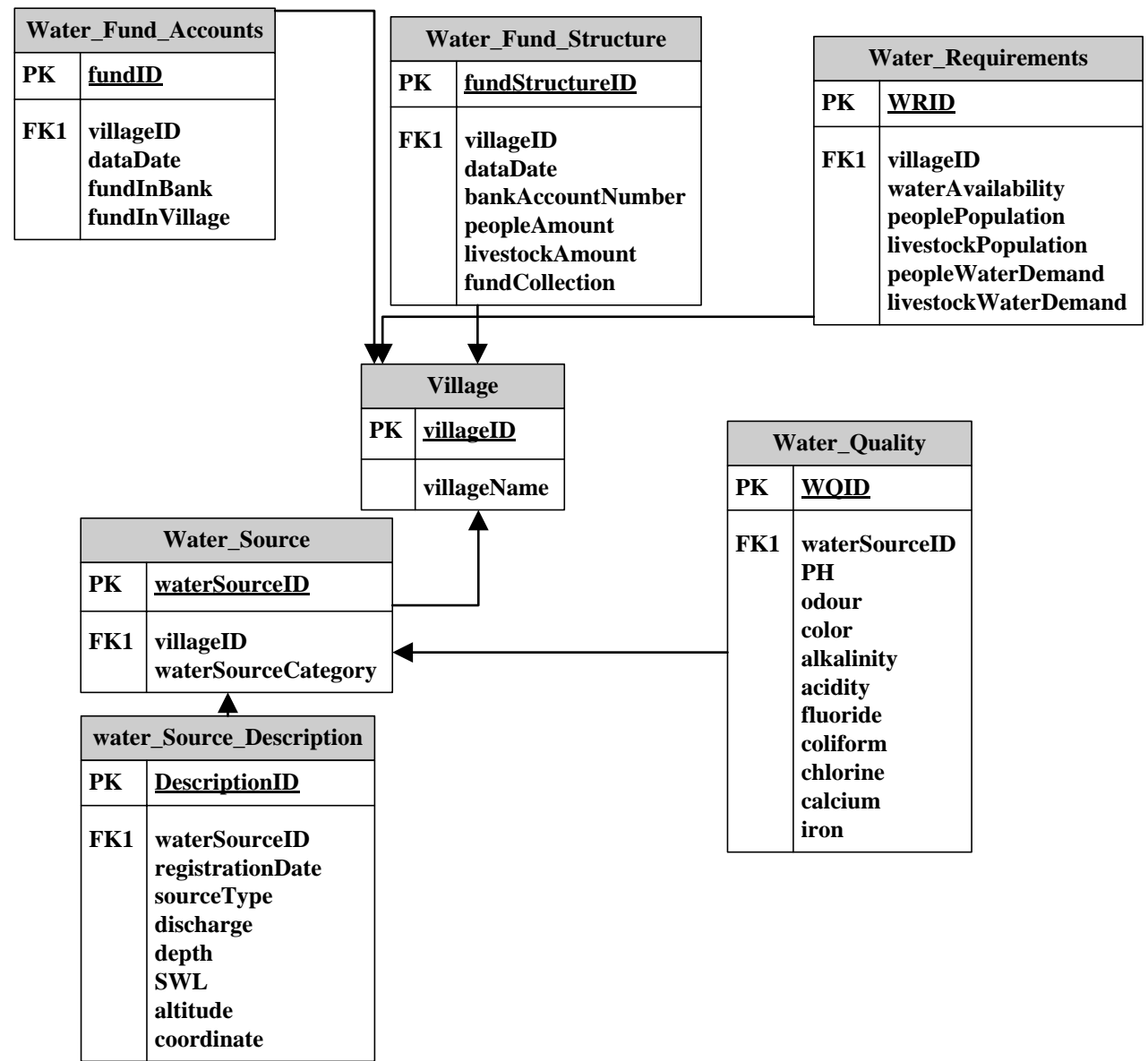

Figure 2: Entity Relationship Diagram for the WAMIS database 


\subsubsection{Entity Relationship Diagram (ERD)}

To clearly demonstrate the relationship among the entities forming up WAMIS database, ERD was used. ERD was also used to indicate the attributes of each entity and their corresponding unique identifiers (Primary keys). Figure 2 depicts an ERD for the WAMIS database.

\subsubsection{Use Cases Diagrams}

In the context of use cases, WAMIS has three actors; DWE, Administrator and Decision Maker. To make clear how each actor interacts with the system and the functions performed, Use Case Diagrams were drawn. Figure 3 depicts what DWE does in the system. DWE is able to: Insert village into database, Record water sources, Insert water fund accounts, Insert water fund structure, Insert village water requirements, and Retrieve information.

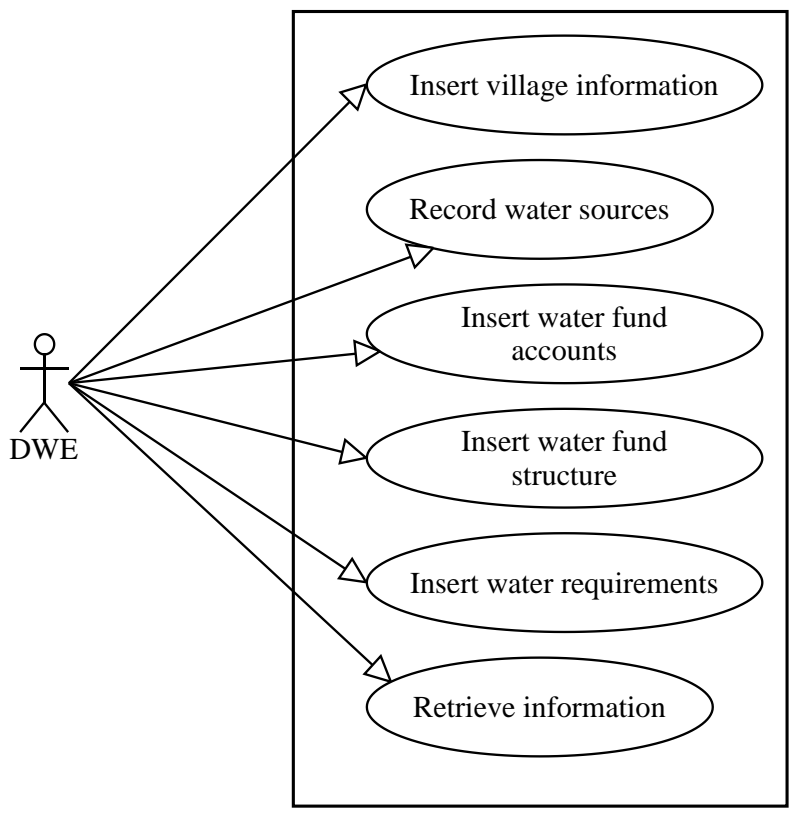

Figure 3: DWE Use Case Diagram

Administrator interacts with the system to manage databases, manage users and perform system setups. Figure 4 shows the Administrator use case diagram.

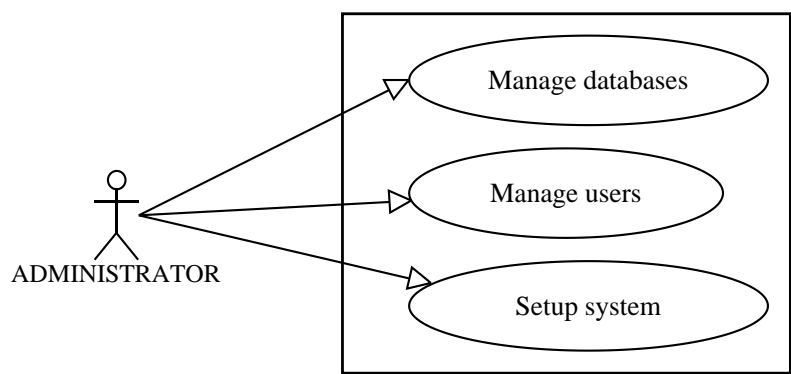

Figure 4: Administrator Use Case Diagram

As depicted in Figure 5, Decision maker can only accesses the system to view reports.

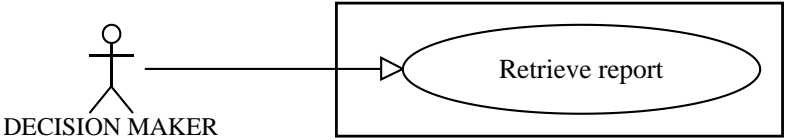

Figure 5: Decision Maker Use Case Diagram

\subsection{WAMIS Mode of Operation}

As a client/server architecture system, WAMIS comprises of front end with a very friendly graphical user interfaces and back end database so called WAMIS database which operates on SQL Server 2008. Users interact with the system through user interfaces to insert and retrieve data from the database. It is a core function of DWE to establish the data that WAMIS requires and inserts the same to the database. WAMIS performs computation on the given data to produce more useful information to enhance decision making. As the data of the available water points keep varying, such as decrease of water quantity produced and variation of water quality, therefore DWE needs to frequently visit the water points for acquiring more recent data to be inputted into WAMIS to update the database.

Figure 6 and Figure 7 depict charts produced by WAMIS to indicate sum of total water demand and balance (in $\mathrm{m}^{3} / \mathrm{day}$ ) respectively for four sample villages (Chakwale, Kilumba, Kitejo and Pingalame). Positive values indicates amount of water remains (surplus) after total consumption, whereas negative values indicates water deficit.

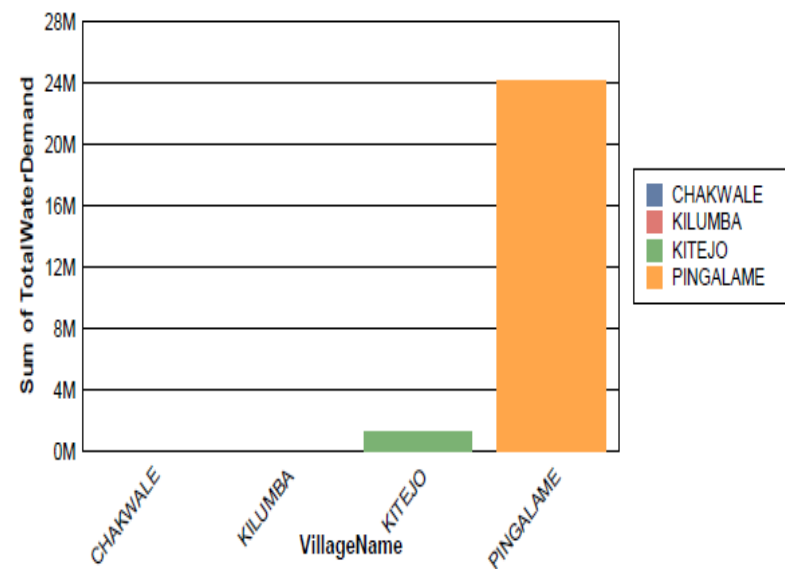

Figure 6: Sum of total water demand $\left(\mathrm{m}^{3} / \mathrm{day}\right)$ per village

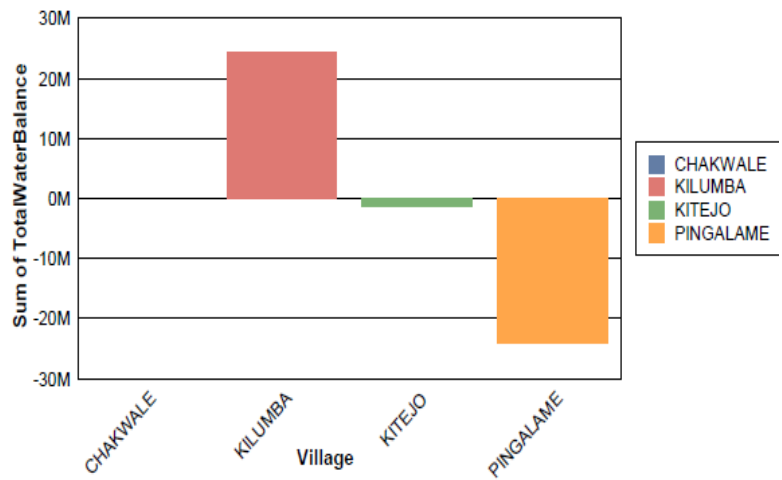

Figure 7: Sum of total water balance $\left(\mathrm{m}^{3} / \mathrm{day}\right)$ per village 


\section{RESULTS AND DISCUSSION}

WAMIS has enabled an efficient means of handling water points' information. Sharing of updated information has been made possible by the database backup and restore feature of WAMIS. DWEs can now easily and at their convenience accesses data centrally stored in a database for quick and precise decision making. Accountability and Transparency in running water points has also improved drastically. Future water projects can now rely on WAMIS database to retrieve baseline information for installation of water points.

To assess the contribution of WAMIS, users were asked for their opinions in rating WAMIS based on the Relevance, Ease of use, Reliability and Performance. In summary, results showed that, WAMIS has revolutionized water points handling. However, there was a call for improvements to make WAMIS more of self-running, in terms of database updating in particular. Figure 8 depicts summary of performance rating (in percentage) of WAMIS.

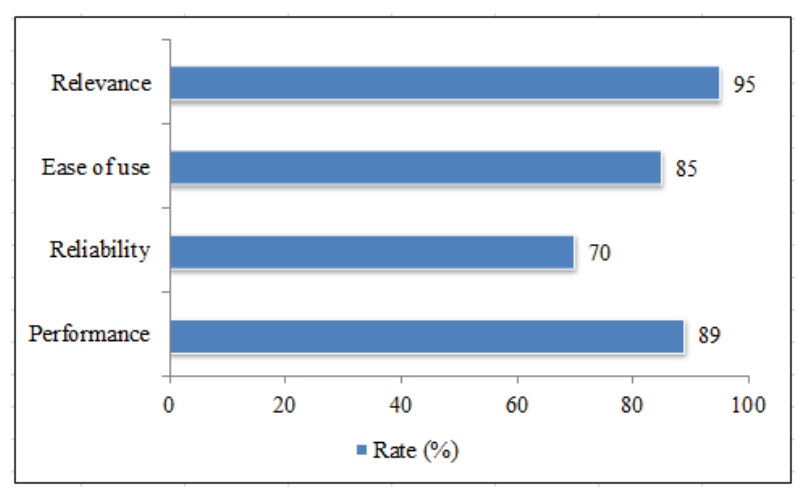

Figure 8: Users' WAMIS performance rating

\section{CONCLUSION}

As the population is fast increasing, water demand is becoming critical. Sufficient, reliable and quality water supply need to be strengthened and improved to meet the realistic water demand. Institutionalization of water points will not reveal the benefits, if installed water points will not be managed effectively for long-lasting existence. This paper has provided details on WAMIS as the ICT solution for effective management of water points. As WAMIS is currently piloted in the field, numerous lessons have been learnt that demand for its improvement. One major improvement that will be addressed in the next phase is to integrate WAMIS with wireless sensor network to update its database in real time. However, the existing decision support services offered by WAMIS are effective and have shown remarkable contributions.

\section{ACKNOWLEDGMENTS}

We would like to express our sincere gratitude to Mr. Ahmed Bwanguzo for his constructive ideas which underpinned the construction of WAMIS. Likewise, we thank District Water Engineers of the districts in which WAMIS has been piloted, for their healthy contribution and cooperation they gave to us throughout the development of WAMIS. We also wish to extend our heartfelt thanks to Mr. Emmanuel C. Mbosso for his technical guidance that verily contributed to the successful completion of WAMIS.

\section{REFERENCES}

[1] Meena Palaniappan, Peter H. Gleick, Lucy Allen, Michael J. Cohen, Juliet Christian-Smith and Courtney Smith. 2010. Clearing the Water. A focus on Water Quality Solutions. UNEP.

[2] Ministry of Health and Social Welfare. June 2013. Tanzania National eHealth Strategy 2013-2018.

[3] SNV. 2012. Achieving Sustainability of Rural Water Supply Services Through application of Water Point Functionality Intervention Framework.

[4] Nicolas Dickinson and Kristof Bostoen. 2013. Using ICT for Monitoring Water Services: From Data to Action. IRC International Water and Sanitation Centre.

[5] Phillipe G. 2011. ICT for Water Effeciency Environmental Monitoring.

[6] F. Rweyemamu. 2014. Water Point Mapping System. Unpublished article.

[7] Joash N. 2011. ICT implementation status in the ministry of water, Tanzania. Unpublished article.

[8] M. Fantozzi, I. Popescu, T. Farnham, F. Archetti, P. Mogre, E. Tsouchnika, C. Chiesa, A. Tsertou, M. Castro Gama and M. Bimpas. 2013. "ICT for efficient water resources management: the ICeWater energy management and control approach". Elsevier, pp 633640, 2013.

[9] Emmanouilidis C and Vlachos A. ICT Systems for Monitoring Water Utility Networks. Accessed from (www.dataconcept.eu) on 02nd July 2014

[10] Radhika D Amlani. 2012. Advantages and Limitations of Different SDLC Models. International Journal of Computer Applications \& Information Technology Vol. I, Issue III, November 2012 (ISSN: 2278-7720). 